\title{
EVALUATING THE MOTOR COMPETENCE OF HEARING IMPAIRED PRIMARY SCHOOL STUDENTS
}

\author{
Mirela Hristova
}

National Sports Academy „Vassil Levski”, Sofia, Bulgaria

\begin{abstract}
Motor Competence (MC) is the ability to perform a wide range of motor activities, relying on adequate levels of motor coordination and physical capacity to achieve.

The aim of this study was to assess the development of basic motor competence indicators among students with hearing impairment aged 7 to 11 years.

The research was done among a total of 91 children aged 7 to 11 years, of whom 42 children with hearing impairment (14 girls, 28 boys) and 49 - with non-impaired hearing (26 girls, 23 boys).

For the purpose of the study, the Kiphard and Schilling battery test-Körperkoordinations Test für Kinder (KTK, 1974) was used. It consists of 4 tests that were measured once. Based on these, four motor quotients were formed, which in turn formed the so-called "Gross Motor Quotient". The results were processed statistically through variation and correlation analysis with the SPSS program.

The results showed significantly lower development of motor competence among students with hearing impairment. The standardized motor quotients of the 4 tests (for boys - all 4; for girls - 3) and the total motor quotient were significantly lower than those of their hearing peers. The lack of significant differences in the mean values of the MQ3 in girls can be explained by the lower performance of the hearing girls compared to the KTK norms.

As a conclusion, the motor competence of children with hearing impairment, assessed by both the overall motor quotient and the individual quotients obtained from the four tests is significantly lower than that of children with non-impaired hearing in primary school age.
\end{abstract}

Key words: Motor Competence, Körperkoordinations Test für Kinder, Students with hearing impairments, Primary school age

\section{INTRODUCTION}

Loss of hearing among children is the most common sensory disorder (among $2.5 \%$ of all newly born), often referred to as "silent epidemic" (Swanepoel, Störbeck, 2008; WHO, 2008). Less than $10 \%$ of newborns have access to early intervention. Data show that more than $90 \%$ of babies with hearing impairment live in the developing world. (Friderichs, et al., 2012; McCormick, 2004; Olusanya, et al., 2008; Olusanya, et al., 2009; Swanepoel, 2008; Swanepoel, Störbeck, 2008)
In Bulgaria there are no statistics of the hearing-impaired people, but it is estimated that there are about 120000 people out of a population of 7000000 people. Approximately 8,000 are hearing impaired children, with 3,000 having severe and profound hearing loss. (data from „Zaslushai se” foundation, 2017)

Hearing impairment among children is a major public health problem associated with long-term academic and communication-related difficulties (Davis, 1997, McCormick, 2004, Rajendran, Roy, 2011). Deafness and re- 
lated peculiarities in behavioral responses and social adaptation have a varying impact on the physical ability of hearing impaired children. There is a higher risk for balance and gross motor skills deficits compared to children with incontinent hearing.

Children with hearing impairment have the same opportunities for cognitive, linguistic, social and physical development as hearing children. A prerequisite for their development is that they live in a favorable environment and are offered incentives that are affordable and responsive to their reduced hearing. (Balkanska, Trosheva-Asenova, 2014)

Motor Competence (MC) is the ability to perform a wide range of motor activities, relying on adequate levels of motor coordination and physical capacity. Therefore, in order for children to confidently carry out a wide range of motor activities in everyday life, they must use adequate levels of motor coordination and physical capacity (Magill and Anderson, 2007). An adequate level of motor competence allows children to easily refine new movements needed to participate in a daily physical activity (Henderson and Sugden, 1992). It has been shown in various studies that the motor competence is predisposed to changes in age from 6 to 12 (Borms, 1986; Gallahue and Donnely, 2007). Early identification of children with moderate motor competence facilitates early rehabilitation in this particular group by using specific programs (Haga, 2009, Bardid, et al., 2013).

Hearing loss relates to the overall function of the central nervous system and the semicircular canals. The effect of the hearing state on the central nervous system in many cases refers to motor skills such as equilibrium, locomotion, and speed of movement. Myklebust states that the results of the deaf during testing of sitting and walking activities do not differ from those with normal hearing capacity. Deaf people, however, operate at a significantly lower level with simultaneous movements, static and dynamic balance and speed. (Myklebust, 1965)

Hearing impairment slows down some reflex movements and organization of coordination at a higher level due to the lack of sounds and other signals from the environment that may be the cause of the slow development of various motor skills. A number of authors report that hearing disturbances cause inability to properly perform the movements. Hearingimpaired people tend to be too loud and too noisy (throwing or striking objects) (Zwierzchowska, et al., 2008).

\section{HYPOTHESIS}

It is clear from the literature review that there are differences in some morpho-functional characteristics among children with impaired hearing.

We assume that there are differences in the MC between the hearing- and hearing-impaired students. The disclosure of the Motor Competency Indicators of hearing-impaired children will allow for targeted activities and improve their opportunities.

In Bulgaria there are no data available for motor competence studies of both groups hearing- and hearing-impaired children aged 7 to 11 years. We assume that there are also differences in term of gender and age in this primary school years.

The results we receive will benefit a number of specialists working in the field of education and public health in order to create specialized programs for better adaptation of children with hearing impairment.

\section{METODOLOGY}

The study was conducted in two schools on the territory of the city of Sofia - secondary school for children with hearing impairment "Prof. Decho Denev" and secondary school 
№51 "Elisaveta Bagryana”, for the period from March to May 2017.

\section{Participants}

The study was conducted among 91 pupils of both genders, aged 7 to 11 years, of whom 42 hearing impaired children (14 girls, 28 boys), without cochlear implants, and 49 children with intact hearing (26 girls, 23 boys). For the purpose of the study, the hearing-impaired children and those with inconvenient hearing were selected along 3 criteria:

- Students fest für Kinder: KTKrom the first to the fifth grade of primary school

- Healthy, non-deficit (except auditory)

- Not previously tested with KTK (Körperkoordinationst, 1974, 2007)

\section{Methods}

A total of 5 motor competence indicators were measured. For this purpose, four tests were applied to the test battery KTK: "Balance backwards walking on beams" (MQ1); "Hopping on one leg over an obstacle" (MQ2); "Jumping laterally" (MQ3); "Shifting platforms" (MQ4).

Each of the four efficiency indicators was then formulated against the specific gender and age reference values on which the KTK battery is established. The sum of the standardized results of the four tests formed a Gross Motor Quotient (GMQ), averaging $100(S D=15)$.

The authors reported a "test-retest" correlation coefficient between 0.80 and 0.96 for the raw scores of the four tests and 0.90 for the total number of MQ points. Therefore, KTK is considered a reliable measurement tool. The gross motor coefficient is considered to be a global indicator of motor competence, on the basis of which children are divided into different categories: Impossible (MQ <56); Disturbed (MQ 56-70); Weak (MQ 71-85); Normal (MQ 86-115); Good (MQ 116-130); Very good (MQ 131-145). (Kiphard \& Schilling, 2007)

\section{Statistical Analysis}

The results of the study were subjected to mathematical and statistical processing with the SPSS program: variance analysis and comparative analysis with Student's t-criterion at a level of significance $\alpha=0.05$

\section{RESULTS AND ANALYSIS}

The subject of our analysis is the motor coefficients of the four tested performance indicators, not the obtained test points. They are based on the specific reference values for the sex and age of the population on the basis of which the KTK was created. The sum of the standardized results of the four test items formed the so-called Gross motor quotient (GMQ) with an average of 100. The coefficients thus obtained allow comparisons to be made between both sexes as well as between the different age groups of students with impaired $(\mathrm{IH})$ and non-impaired hearing $(\mathrm{NIH})$.

Analysis of Motor Competency Indicators among hearing $(H)$ and hearing impaired (HI) girls.

The results of the conducted study on motor competence indicators of girls with impaired and intact hearing are presented in table 1 and 2 .

Girls reported values of motor quotients with significant differences in favor of hearing students. Significant differences were observed in 3 of the 4 indicators for motor competence surveyed - MQ1 "Balance backwards walking on beams" ( $P t=97 \%)$, MQ2 "Hopping on one leg over an obstacle" $(P t=99.9 \%)$ and MQ4 "Shifting Platforms" $(P t=98.3 \%)$, as well as the gross motor quotient (GMQ Pt $=99.6 \%$ ). For the above-mentioned indicators with a guarantee probability exceeding the critical 95\%, we can assume with confidence the rejection of the Zero hypothesis and the acceptance of the alternative one, verifying the existence of significant differences for the studied statistical samples. 
Table 1. Biostatistical data on motor competence coefficients among hearing impaired (HI) girls

\begin{tabular}{cccccc}
\hline Indicators for HI girls & MQ1 & MQ2 & MQ3 & MQ4 & GMQ \\
\hline X & 94,6 & 86,6 & 79,9 & 92,1 & 85,6 \\
S & 17,4 & 18,6 & 18,3 & 18,1 & 19,5 \\
V & $18 \%$ & $21 \%$ & $23 \%$ & $20 \%$ & $23 \%$ \\
Ex & 1,8 & 0,6 & $-0,3$ & 3,4 & 1,0 \\
As & $-0,6$ & $-0,5$ & $-0,3$ & $-1,6$ & $-0,7$ \\
Max & 123,0 & 117,0 & 109,0 & 115,0 & 114,0 \\
Min & 53,0 & 45,0 & 43,0 & 43,0 & 40,0 \\
T & 2,26 & 3,77 & 1,12 & 2,65 & 3,04 \\
Pt [\%] & 97,0 & 99,9 & 73,1 & 98,3 & 99,6 \\
\hline
\end{tabular}

Table 2. Biostatistical data on motor competence coefficients among hearing $(H)$ girls

\begin{tabular}{cccccc}
\hline Indicators for H girls & MQ1 & MQ2 & MQ3 & MQ4 & GMQ \\
\hline X & 105,3 & 109,0 & 85,7 & 105,8 & 101,7 \\
S & 12,3 & 17,5 & 13,7 & 12,1 & 13,9 \\
V & $12 \%$ & $16 \%$ & $16 \%$ & $11 \%$ & $14 \%$ \\
Ex & 1,2 & 0,5 & $-0,3$ & 0,8 & 0,1 \\
As & $-0,1$ & $-0,7$ & $-0,5$ & 0,6 & $-0,7$ \\
Max & 133,0 & 137,0 & 106,0 & 134,0 & 122,0 \\
Min & 74,0 & 65,0 & 54,0 & 84,0 & 69,0 \\
T & 2,26 & 3,77 & 1,12 & 2,65 & 3,04 \\
$\mathrm{Pt}[\%]$ & 97,0 & 99,9 & 73,1 & 98,3 & 99,6 \\
\hline
\end{tabular}

The mean values of hearing $(\mathrm{H})$ and hearing impaired (HI) girls were in the "Normal" category (MQ between 86 and 115) for motor competence in 3 of the 4 motor quotients tested: "Balance backwards walking on beams" - HI (MQ1 = 94.6); H (MQ1 = 105.3); "Hopping on one leg over an obstacle" - HI (MQ2 = 86.6); H (MQ2 = 109.0); "Shifting Platforms" - HI (MQ4 = 92.1); H (MQ4 = 105.8). The mean values for the two groups of girls obtained in the test "Jumping laterally" (HI (MQ3 = 79.9), H (MQ3 = 85.7)) were in the "Weak" category (MQ between 71 and 85) for motor competence.

The Gross motor quotient is considered to be a global indicator of motor competence. The results obtained among girls showed significantly lower performance of those with hearing impairment compared to their hearing peers. Mean values for the gross motor quotient $(\mathrm{GMQ}=85.6)$ for hearing impaired girls were in the "Weak" category for motor competence, while values for hearing students were in the "Normal" category (GMQ = 101.7).

Analysis of Motor Competency Indicators among hearing $(H)$ and hearing impaired (HI) boys.

The results of the conducted study of motor competence indicators among boys with impaired and intact hearing are presented in table 3 and 4.

The values obtained of the motor quotients in the hearing- and hearing-impaired boys were predominantly in favor of the hearing students. Significant differences were observed in all of the 4 tested indicators: MQ1 $(P t=99.9 \%)$; MQ2 $(P t=100 \%) ;$ MQ3 (Pt $=100 \%)$; MQ4 $(P t=99.6 \%)$, as well as the gross motor quotient (GMQ $P t=100 \%$ ). For the above-mentioned indicators with a guarantee probability exceeding the critical $95 \%$, we can assume with confidence the rejection of the Zero hypothesis and the acceptance of the alternative one, verifying the existence of significant differences for the studied statisti- 
cal samples.

Table 3. Biostatistical data on motor competence coefficients among hearing impaired (HI) boys

\begin{tabular}{cccccc}
\hline Indicators for HI boys & MQ1 & MQ2 & MQ3 & MQ4 & GMQ \\
\hline X & 89,1 & 90,0 & 80,6 & 89,6 & 84,2 \\
S & 13,1 & 15,2 & 11,8 & 15,4 & 13,2 \\
V & $15 \%$ & $17 \%$ & $15 \%$ & $17 \%$ & $16 \%$ \\
Ex & $-1,0$ & 0,2 & $-0,3$ & $-1,4$ & $-0,9$ \\
As & 0,2 & 0,2 & 0,1 & $-0,1$ & $-0,1$ \\
Max & 112,0 & 120,0 & 107,0 & 113,0 & 106,0 \\
Min & 70,0 & 54,0 & 58,0 & 66,0 & 59,0 \\
T & 3,70 & 4,32 & 4,27 & 2,99 & 4,78 \\
Pt [\%] & 99,9 & 100,0 & 100,0 & 99,6 & 100,0 \\
\hline
\end{tabular}

Table 4. Biostatistical data on motor competence coefficients among hearing $(H)$ boys

\begin{tabular}{cccccc}
\hline Indicators for H boys & MQ1 & MQ2 & MQ3 & MQ4 & GMQ \\
\hline X & 101,7 & 107,2 & 94,4 & 103,4 & 101,4 \\
S & 10,6 & 12,7 & 11,1 & 17,7 & 12,3 \\
V & $10 \%$ & $12 \%$ & $12 \%$ & $17 \%$ & $12 \%$ \\
Ex & $-1,3$ & 0,0 & $-0,5$ & 2,2 & $-0,2$ \\
As & 0,3 & $-0,9$ & 0,3 & $-0,7$ & $-0,1$ \\
Max & 119,0 & 122,0 & 118,0 & 137,0 & 122,0 \\
Min & 87,0 & 76,0 & 76,0 & 53,0 & 74,0 \\
T & 3,70 & 4,32 & 4,27 & 2,99 & 4,78 \\
Pt [\%] & 99,9 & 100,0 & 100,0 & 99,6 & 100,0 \\
\hline
\end{tabular}

The mean values of boys with impaired hearing were in the "Normal" category (MQ between 86 and 115) for motor competence for 3 of the 4 motor quotients tested: "Balance backwards walking on beams" (MQ1 = 89.1); "Hopping on one leg over an obstacle" (MQ2 = 90.0); "Sifting Platforms" (MQ4 = 89.6). While the mean values obtained from the test "Jumping laterally" (MQ3 = 80.6) were in the "Weak" category for motor competence.

Among hearing boys, the mean values of the motor quotients of all 4 tests were in the ,Normal" category for motor competence (MQ1 = 101.7; MQ2 = 107.2; MQ3 = 94.4; MQ4 = 103.4).

In terms of the Gross motor quotient, the results obtained among the boys showed significantly lower performance of those with hearing impairment compared to their hearing peers. The average values for boys with impaired hearing $(\mathrm{GMQ}=84.2)$ were in the "Weak" category, while values for students with intact hearing (GMQ $=101.4)$ were in the „Normal” category for motor competence.

\section{Summary of motor competence indicators} for hearing-and hearing-impaired students in primary school.

The execution of the tests requires a combination of different physical qualities such as flexibility, explosive force of lower limbs, equilibrium resistance, planning and coordination. We find significant differences between children with hearing impairment and hearing children in terms of the results of the motor quotients.

The results of students with hearing impairment of the 4 motor quotients (for boys all 4 for girls - 3) and the gross motor quotient (GMQ) were significantly weaker than those of their hearing peers.

The absence of significant differences in girls from the test "Jumping laterally" MQ3 may be explained by the lower performance 
of some of the hearing girls compared to KTK standards.

From the analysis of the obtained results we also find a gradual decrease of the average values of the motor competency quotients as the age of the studied students of both sexes grows. This affects considerably more nega- tively on students with hearing impairment, where the motor competence gradually goes from normal to weak.

The classification of the values for the Gross Motor Quotient (GMQ) for hearing (H) and hearing impaired (HI) students in primary school age is presented in table 5 .

Table 5. KTK standards for GMQ and distribution of the results obtained for hearing $(H)$ and hearing impaired (HI) students

\begin{tabular}{ccccccc}
\hline \multirow{2}{*}{ Values for GMQ } & \multirow{2}{*}{ Category } & \multicolumn{2}{c}{ HI } & \multicolumn{3}{c}{ H } \\
\cline { 4 - 7 } & & & № & \% & № & \% \\
\hline $131-145$ & 2 & Very Good & - & - & - & - \\
$116-130$ & 14 & Good & - & - & 7 & 14,3 \\
$86-115$ & 68 & Normal & 22 & 52,4 & 37 & 75,5 \\
$71-85$ & 14 & Weak & 13 & 30,9 & 4 & 8,2 \\
$56-70$ & 2 & Disturbed & 6 & 14,3 & 1 & 2 \\
MQ $<56$ & 0 & Impossible & 1 & 2,4 & - & - \\
\hline
\end{tabular}

The results showed that good motor competence was $14.3 \%$ of the hearing children, which completely matches the expected normal percentage distribution on the KTK. None of the children with hearing impairment falls into this category despite the fact that $11.9 \%$ of them are engaged in extra-sporting out-ofschool activities.

The main percentage of the children tested showed normal motor competence levels (HI $(52.4 \%)$; H (75.5\%)). We find that for HI this result is relatively lower than the average $(68 \%)$, and for the $\mathrm{H}$ is relatively higher.

The percentage of children falling under the "Weak Motor Competence" category is disturbing. It includes a significantly higher percentage of students with hearing impairment (30.9\%) than the average (14\%). As for hearing children, their percentage is relatively low $(8.2 \%)$, which is a good indicator.

With "Disturbed Motor Competence" are $14.3 \%$ of the surveyed hearing-impaired students, which is seven times the norm $(2 \%)$, while the percentages of their hearing peers coincide with the average values.

Of the surveyed children with hearing impairment, one child (2.4\%) was rated as hav- ing an "Impossible Motor Competence", which implies the existence of additional deficits for which we were not aware of.

In his study, Long (1932) did not find significant differences between deaf and hearing children (aged between 8 to 17 years) in bimanual coordination, eye-arm coordination, and response time. But he reported significantly lower results for the deaf when walking back on the beam, which overlaps with our results.

The motor development of hearing-impaired children from 4 to 12 years of age was also investigated by the Körperkoordinations Test für Kinder (1974), the researchers at the University of Gent (Belgium) reported significantly weaker results in two of motor tests for deaf children. Hearing children had a significantly better result when walking back on the beams compared to those with impaired hearing. Also, significantly weaker was the indicator among the children without cochlear apparatus in "Hopping on one leg over an obstacle" test. In all other results, children with normal hearing performed slightly better than the deaf with and without cochlear apparatus (Gheysen et al., 2007).

Brunt and Broadhead (1982) examined the motor coordination of 154 deaf children (aged 
7-14) through the short form of BOT-2 (Bruininks, 1978; Bruininks \& Bruininks, 2005). The results revealed disadvantages of hearing-impaired children in terms of balance, bilateral coordination and reaction rate. Better values were obtained only in visual motor control, which may be due to the continuous use of hands for communication.

Other researchers explored separate fundamental motor skills of children aged 3 to 14 through the SIGMA (Scale of Intra Gross Motor Assessment, Loovis \& Ersing, 1979) and reported that a large proportion of children aged 7 and 8 years old had not yet reached motor maturity and were lagging behind the hearing children with regard to activities related to running, kicking, gripping, throwing, skipping. (Butterfield, 1986; Butterfield, et al., 1992). Fundamental motor skills and the ability to combine them are required for developing good motor competence.

In a vast study of the reliability of various postural stability tests, in addition to those of posturography, De Kegel, et al. (2010) also applied 4 clinical balancing tests: standing on one leg with open eyes; standing on one leg with closed eyes; 2 of the 4 KTK Tests (walking along the beams, hopping on one leg over an obstacle). Clinical tests were those that showed the highest reliability against other tests among children with impaired and intact hearing. They also reported a relatively lower performance of hearing-impaired children than the hearing, suggesting children with hearing impairment were able to compensate.

The influence of different variables (localization of the damage, level of hearing loss, development of fundamental motor skills, balance) on MC of hearing-impaired children can be considered as future research directions for better understanding.

Different authors focus on the negative effect that low motor competence has on: physical ability (Hands \& Larkin, 2006; Stodden et al., 2008); physical activity (Cairney et al., 2006;
Cairney et al., 2007; Okely et al., 2001); overweight (D'Hondt, et al., 2012) and psychological concepts as self-esteem and motivation for sports (Rose, et al., 1997; Vedul-Kjelsas, et al., 2011). A Haga study (2009) establishes a positive link between motor competence and healthrelated capacity (EDC) among 9-10-year-old children.

There is a hypothesis that children with low $\mathrm{MC}$ are not physically active enough, which in turn may lead to reduced levels of physical ability compared to children with high motor competence (Hands and Larkin, 2006; Haga, 2009; Cairney, et al., 2011). Also, a combination of low physical activity and motor competence can contribute to early exhaustion (Okely, et al., 2001; Hands \& Larkin, 2006) and thus further reduce the possibilities for developing motor skills during playground play, leisure time sports, and more.

\section{CONCLUSION}

From the results obtained, we have reason to conclude that hearing impairment and limited intentional and unintentional motor activity have a significant influence on the motor competency of the students in primary school.

Significantly poor results for hearing impaired children with almost all motor ratios (excluding MQ3 in girls) indicate significant health risks: direct (combining basic motor skills related to health-related capacity); indirect (in time, would have an impact as part of the motor capability).

Changed motor activity in primary school age compared to previous years does not stimulate the development of motor competency of children, and this has a significantly negative impact on students with impaired hearing.

Our research shows that children in primary school age need additional motor activity. It is recommended for the good psycho-physical development and health of the hearing students and is obligatory for the hearing impaired. 


\section{REFERENCES}

Balkanska, N., Troshleva-Asenova, A. (2014). Inclusion of the child with hearing impairment in the educational environment, Sofia, Fenomen // Бакалска, Н., Трошева-Асенова, А. (2014). Приобщаване на детето с увреден слух в образователната среда, София, Феномен.

Bardid, F., Deconick, F., Descamps, S., Verhoeven, L., De Pooter, G., Lenor, M., D’Hondt, E. (2013) The effectivness of fundamental motor skill intervation in pre-schoolers with motor problems depends on gender but not environmental context, Research in Developmental Disabilities, 34, 12, pp. 4571-4581.

Borms, J. (1986). The child and exercise: on overview, J. Sports Sci., 4 (1), 3-20.

Brunt, D. \& Broadhead, G. (1982). Motor proficiency traits of deaf children, res. Q., 53, pp. 236-238.

Butterfield, S. (1986). Gross motor profiles of deaf children, Percept. Motor Skills, Vol. 62: pp. 68-70.

Butterfield, A., van der Mars, H., Chase, J. (1992). Fundamental motor skill performances of deaf and hearing children ages 3 to 8, Clinical Kinesiology, Vol. 46.

Bruininks, R. H., (1978). Bruininks-Oseretsky test of motor proficiency - Owner's manual, Circle Pines, MN: American Guidance Service.

Bruininks, R., \& Bruininks, B. (2005). Bruininks-Oseretsky test of motor proficiency $\left(2^{\text {nd }}\right.$ ed.), Minneapolis, MN, NCS Pearson.

Cairney, J. Hay, J., Faught, B., Corna, L. \& Flouris, A. (2006). Developmental coordination disorder, age, and play; a test of divergence in activity deficit with age hypothesis, Adapt. Phys. Activ. Q., 23, pp. 261-276.

Cairney, J. Hay, J., Faught, B., Corna, L., Flouris, A. \& Klentrau, P. (2007). Developmental coordination disorder and cardiorespiratory fitness in children, Pediatr. Exerc. Sci., 19, pp. 20-28.
Cairney, J., Hay, J., Veldhuizen, S. \& Faught, B. (2011). Trajectories of cardiorespiratory fitness in children with and without developmental coordination disorder; a longitudinal analysis., Brit. J. Sports Med., 45 (15), pp. 1196-1201.

Davis, A. (1997). Epidemiology of hearing impairments in Scott Brown's Otolaringology, pp. 18-19.

D'Hondt, E., Deforche, B., Gentier, I., Bourdeaudhuij, I., Vaeyens, R., Philippaerts and Lenoir, M. (2012). A longitudinal analysis of gross motor coordination in overweight and obese children versus normal-weight peers, International Journal of Obesity, 37, pp. 61-67.

De Kegel A., Dhooge I., Peersman W., Rijckaert J., Baetens T., Cambier D., Van Waelvelde H. (2010.) Constructor validity of the assessment of balance in children who are developing typically and children whit hearing inmpairments, Phys. Ther., 90 (12), pp. 1783-1794.

Friderichs, N., Swanepeol, D.W., Hall, J. (2012). Efficacy of a community based infant hearing screening programme utilising existing clinical personnel in Western Cape, South Africa. Int J Pediatr Otorhinolaryngol, 76 (4), pp. 552-59.

Gallahue, D., Donnely, F. (2007). Developmental Physical Education for all Children ( $4^{\text {th }}$ ed.), Human Kinetics.

Gheysen, F., Lotts, G., Waelvelde, H. (2007). Motor Development and Cochlear Implantation, Journal of Deaf Studies and Deaf Education, vol. 13, 2.

Haga, M. (2009). Physical fitness in children with high motor competence is different from that in children with low competence, Physical therapy, 89, pp. 1089-1095.

Hands, B. Larkin, D. (2006). Physical fitness differences in children with and without motor learning difficulties, Eur. J. Spec. Needs. Educ, 21 (4), pp. 447-56.

Henderson, S., and Sugden, D. (1992). Movement assessment battery for children, Manual, London, Psychological Corporation. 
Kiphard, EJ., Schilling, F. (2007). E. Körperkoordinationstest für Kinder: KTK.

Long, J. (1932). Motor abilities of deaf children, Contribution to Education\#514, Columbia University Teacher's College, New York.

Loovis, E., Ersing, W. (1979). Assessing and programming gross motor development for children, Health and Human Performance books. 1., Mohican Textbook Pub. Co, Loudonville, Ohio.

Magill, R., Anderson, D. (2007). Motor learning and control: Concepts and applications, vol. 11, New York: McGraw-Hill.

McCormick, B. (2004). Screening and surveillance for hearing impairment in preschool children, Paediatric Otolaryngology, Vol. 6.

Myklebust, H. (1965). The Psychology of Deafness, Grune and Stratton, New York, London.

Okely, A., Booth, M., Patterson, J. (2001). Relationship of physical activity to fundamental movement skills among adolescents, Med. Sci., Sports Exerc., 33, pp. 1899-1904.

Olusanya, B., Somefun, A., Swanepoel, D. (2008). The need for standardization of methods for worldwide infant hearing screening: A systematic review. Laryngoscope, 188, pp. 1830-36.

Olusanya, B., Emokpae, A., Renner, J., Wirz, S. (2009). Costs and performance of early hearing detection programmes in Lagos, Nigeria, $R$ Soc Trop Med Hyg, 103, pp. 179-86.

Rajendran, V.\& Roy, F. G. (2011). An overview of motor skill performance and balance in hearing impaired children, Italian Journal of Pediatrics, pp. 37-33.

Rose, B., Larkin, D., Berger, B. (1997).
Coordination and gender influences on the perceived competence of children, Adapted Physical Activity Quarterly, 14, pp. 210-221.

Schilling, F., Kiphard, E. (1974, 2007), Körperkoordinationstest für Kinder: KTK, Göttingen Hogrefe, Germany.

Stodden, D., Goodway, J., Langendorfer, S., Robertson, M., Rudisill, M., Garcia, C., \& Garcia, L. (2008). Developmental perspective on the role of skill competence in physical activity, an emergent relationship, Quest, 60, pp. 290-306.

Swanepoel, D. (2008). Early intervention for hearing loss in South Africa: Cost benefits and current status, Ndiyeva Audiology Conference.

Swanepoel, D., Störbeck, C. (2008). EHDI Africa: Advocating for infants with hearing loss in Africa. Int J Audiol; 47 (Suppl 1), S1-S2.

Vedul-Kjelsas, V., Sigmundson, H., Stendotter, A., Haga, M. (2011). The relationship between motor competence, physical fitness and self perception in children, Child: Care, health and development, 38, pp. 394-404.

World Health Organisation. Deafness and hearing impairment. (2008). Available at: http:// www.who.int/mediacentre/factsheets/fs300/en/ index.html (accessed 25 August 2012).

Zwierzchowska, A., Gawlik, K., Grabara, M. (2008). Deafness and motor abilities level, Biology of Sport, Vol. 25 №3, pp. 263-274.

„Zaslushai se” Foundation: https://zaslushaise.bg/ (accessed 7 November 2017) // Фондация „Заслушай се”, (2017).

\section{Corresponding author:}

Mirela Hristova

Theory and Methodology of Physical Therapy

National Sports Academy "Vassil Levski"

Studentski grad, 21, Acad. Stefan Mladenov str.

Sofia 1700, Bulgaria

E-mail: mirahrist@yahoo.com 